\title{
Efeitos de diferentes substratos e temperaturas na germinação de sementes de Foeniculum vulgare
}

RANZANI, R.E.'; LUZ, P.B. ${ }^{*}$; MAROSTEGA, T.N.'; PAIVA SOBRINHO, S. ${ }^{1}$

Universidade do Estado de Mato Grosso, Cidade Universitária, Departamento de Agronomia, Avenida Santos Dumont, s/n. Bairro Santos Dumont, CEP 78200-000, Cáceres - Brasil. *Autor para correspondência: raphael_ ranzani@hotmail.com

\begin{abstract}
RESUMO: O funcho (Foeniculum vulgare) é uma espécie medicinal nativa da Europa e amplamente cultivada em todo o Brasil. Possui propriedades carminativas, digestivas e diuréticas. Dada a grande importância dessa espécie no âmbito medicinal, objetivou-se com este trabalho avaliar o efeito de diferentes substratos e temperaturas na germinação de sementes de funcho. Os tratamentos foram compostos de duas temperaturas sendo uma constante de $20^{\circ} \mathrm{C}$ e outra alternada de $25-30^{\circ} \mathrm{C}$ e três diferentes substratos: papel mata borrão (Germitest), areia e vermiculita, em esquema fatorial $3 \times 2$, com 4 repetições de 25 sementes. Foi avaliado o índice de velocidade de germinação (IVG), porcentagem de germinação (PG), comprimento da radícula (CR), massa fresca (MF) e seca (MS) de plântulas. A temperatura de $20^{\circ} \mathrm{C}$ proporcionou maiores IVG, porcentagens de germinação, comprimento de radícula e massa seca. A germinação de sementes de funcho não foi influenciada pelos diferentes substratos testados. Pelos resultados, conclui-se que a condição que permitiu maior porcentagem de germinação das sementes de funcho foi a temperatura de $20^{\circ} \mathrm{C}$ atingindo $91 \%$ de germinação. Palavras chaves: Funcho, planta medicinal, germinação.
\end{abstract}

\begin{abstract}
Effects of substrate and temperature on the germination of Foeniculum vulgare seeds. Fennel (Foeniculum vulgare) is a medicinal plant native to Europe that is widely cultivated throughout Brazil. It has carminative, digestive, and diuretic properties. Given the great importance of this species in medicine, the objective of this study was to evaluate the effect of different substrates and temperature on the germination of fennel seeds. The treatments consisted of two temperatures - one a constant $20^{\circ} \mathrm{C}$, and the other alternating from 25 to $30^{\circ} \mathrm{C}$ - and three different substrates: blotting paper (Germitest), sand, and vermiculite, in a 3 $\times 2$ factorial with four replications of 25 seeds. The germination speed index (GSI), percentage of germination (PG), radicle length, and fresh (FM) and dry mass (DM) of seedlings were evaluated. The $20^{\circ} \mathrm{C}$ temperature resulted in higher GSI, germination percentage, root length and dry mass. The fennel seed germination was not influenced by the different substrates tested. From the results, we concluded that the condition that allowed greatest percentage of fennel seed germination temperature was $20^{\circ} \mathrm{C}$, reaching $91 \%$ germination.
\end{abstract}

Keywords: fennel, medicinal plant, germination.

\section{INTRODUÇÃO}

O funcho (Foeniculum vulgare Miller) é uma espécie medicinal nativa da Europa e cultivada em todo o Brasil. Apresenta flores amarelas, dispostas em umbelas e frutos são diaquênios (Lorenzi \& Matos, 2002). Possui propriedades carminativas, digestivas e diuréticas. O óleo extraído do funcho é utilizado na fabricação de licores e perfumes. As sementes são utilizadas na confeitaria como aromatizantes em pães, bolos e biscoitos (Martins et al., 1998).

O processo germinativo inicia-se com a embebição e a consequente retomada das atividades metabólicas paralisadas por ocasião da maturação fisiológica das sementes. Para que isso ocorra, alguns requisitos são fundamentais, como as sementes estarem viáveis e as condições ambientais estarem favoráveis. Para que uma semente viável possa germinar são necessários: suprimento de água em quantidade suficiente; temperatura adequada; substrato, bem como presença de luz para determinadas espécies (Carvalho \& Nakagawa, 2000). 
O grau de exigência desses fatores é variável entre as espécies e determinado pelo genótipo e pelas condições ambientais prevalecentes durante a germinação das sementes (Mayer \& PoljakoffMayber, 1989).

A temperatura para a germinação de sementes apresenta grande influência, tanto na porcentagem final de germinação como também na velocidade do processo germinativo. A temperatura influencia ainda na absorção de água pela semente (Shull, 1920) e as reações bioquímicas que regulam o metabolismo necessário para iniciar o processo de germinação (Carvalho \& Nakagawa, 2000).

Os substratos utilizados nos testes de germinação também apresentam grande influência na germinação, uma vez que fatores como estrutura, aeração, capacidade de retenção de água, grau de infestação de patógenos, etc., podem variar de acordo com o tipo de material utilizado (Popinigis, 1977). A escolha do substrato deve levar em conta as exigências das sementes, em relação ao seu tamanho, formato, entre outros (Brasil, 2009).

Apesar do aumento considerável de conhecimento relativo à análise de sementes de espécies medicinais, gerados por pesquisas nestas duas últimas décadas, a maioria delas carece de subsídios básicos referentes às condições ideais de germinação e informações referentes ao vigor. Este fato pode ser comprovado através das Regras para Análise de Sementes (Brasil, 2009), onde são encontradas poucas informações sobre a metodologia para análise de sementes dessas espécies que são merecedoras de vários estudos. Não apenas quanto à identificação correta do princípio ativo fitoterápico, como, também, a avaliação dos efeitos de fatores como luz, temperatura, água e substrato no comportamento germinativo.

Pelo grande interesse medicinal e comercial e a escassez de relatos na literatura sobre a germinação das sementes de funcho, objetivou-se, neste trabalho, estudar o efeito da temperatura e do substrato na germinação de sementes dessa espécie.

\section{MATERIAL E MÉTODOS}

O experimento foi conduzido no Laboratório de Sementes e Plantas Ornamentais da Universidade do Estado de Mato Grosso (UNEMAT) em Cáceres MT. As sementes de funcho foram obtidas no horto de plantas medicinais e nativas do Instituto Padre João Peter de Lucas do Rio Verde-MT.

Foi realizado um processo de assepsia das sementes, em solução de álcool $70 \%$ (v/v) durante 1 minuto, e em hipoclorito de sódio $(2,5 \%$ de cloro ativo) por 5 minutos, em seguida lavadas em água destilada.

Após tratamento foram iniciados os testes de germinação e vigor, a fim de estudar a influência de duas temperaturas e três substratos no potencial fisiológico das sementes de Foeniculum vulgare. As temperaturas estudadas foram de $20^{\circ} \mathrm{C}$ constante e 25-30 ${ }^{\circ} \mathrm{C}$ alternadas, com fotoperíodo de 12 horas de luz e 12 horas de escuro para ambas temperaturas. Para isso, utilizou-se câmara de germinação do tipo BOD. Os substratos testados foram: papel mata borrão, areia (esterilizada) e vermiculita, acondicionadas em caixas de acrílico tipo Gerbox.

Os tratamentos foram esquematizados em delineamento inteiramente casualizado, em esquema fatorial $3 \times 2$, com 4 repetições de 25 sementes.

A avaliação da germinação foi realizada diariamente, considerando-se germinada a semente que rompesse o tegumento e emitisse radícula com pelo menos $2 \mathrm{~mm}$ de comprimento. Foi avaliada a porcentagem de germinação, o comprimento da radícula $(\mathrm{CR})$, a massa fresca e seca de plântulas, bem como o índice de velocidade de germinação (IVG), empregando-se a fórmula proposta por Maguire (1962):

As contagens das sementes germinadas foram efetuadas diariamente, no mesmo horário, durante o período de 14 dias.

Comprimento médio da radícula: foi obtido somando-se as médias de cada repetição e dividindose pelo número de radículas normais mensuradas, com resultados expressos em centímetros $(\mathrm{cm})$, conforme descritos por Nakagawa (1999).

Massa fresca: o peso médio da massa fresca foi obtido somando-se as médias de cada repetição e dividindo-se pelo número de plântulas normais mensuradas, com resultados expressos em miligramas (mg).

Massa seca: o peso médio da massa seca foi obtido somando-se as médias de cada repetição e dividindo-se pelo número de plântulas normais mensuradas, provenientes do teste anterior (peso de massa fresca), acondicionadas em sacos de papel e secas em estufa a $60^{\circ} \mathrm{C}$, até a obtenção de massa constante (48h). Em seguida, as repetições foram pesadas em balança de precisão $0,001 \mathrm{~g}$, sendo os resultados expressos em miligramas $(\mathrm{mg})$ por plântula, conforme Nakagawa (1999).

Os dados foram submetidos ao teste de normalidade de Kolmogorov-Smirnov, utilizandose o software computacional GENES (Cruz, 2006). Quando verificada normalidade dos dados foi realizada a análise de variância e as médias comparadas pelo teste de Tukey a $1 \%$ de probabilidade, com o auxílio do programa computacional SISVAR (Ferreira, 2008). 


\section{RESULTADOS E DISCUSSÃO}

Conforme a análise de variância (Tabela 1) verificou-se que as sementes de funcho apresentaram diferença significativa somente na fonte de variação temperatura a $1 \%$ de probabilidade, não sendo significativo nas outras fontes de variação não havendo interação substrato $x$ temperatura.

Em relação a porcentagem de germinação de sementes de Foeniculum vulgare, submetidas a diferentes temperaturas e substratos, a temperatura constante de $20^{\circ} \mathrm{C}$ apresentou maiores médias quando comparada com a temperatura alternada de $25-30{ }^{\circ} \mathrm{C}$, conforme Tabela 2. Resultados semelhantes foram obtidos na germinação de sementes de marcela (Achyrocline satureioides Lam) (Ikuta \& Barros, 1996), alface (Lactuca sativa) (Menezes et al., 2000), cenoura (Daucus carota L) (Carneiro \& Guedes, 1992), anis (Pimpinella anisum) (Takarashi et al., 2000; Teixeira et al., 2003) e funcho (Foeniculum vulgare) (Stefanello et al., 2006).

Resultado semelhante foi encontrado por (Stefanello et al, 2006) trabalhando com sementes de Foeniculum vulgare, que concluíram que a porcentagem de germinação é influenciada pela temperatura, sendo os maiores índices de germinação alcançadas na temperatura de 20
${ }^{\circ} \mathrm{C}$, e em relação a luz, a germinação apresenta comportamento indiferente, sendo classificada como insensível à luz, por germinar tanto na presença como na ausência de luz (Labouriau, 1983).

Segundo Bewley \& Black (1994), nas sementes da maioria das espécies vegetais, a temperatura afeta tanto a capacidade quanto a velocidade de germinação. As sementes têm o máximo de germinação em temperaturas consideradas ótimas, sendo específicas para cada espécie. As temperaturas inferiores ou superiores à ótima tendem a reduzir a velocidade do processo germinativo, expondo as plântulas por maior período a fatores adversos, o que pode levar à redução no total de germinação.

Martins et al. (2007) obtiveram resultados semelhantes trabalhando com sementes de Chenopodium ambrosioides L. De acordo com Carvalho \& Nakagawa (2000), as temperaturas inferiores ou superiores à ótima tendem a reduzir a velocidade do processo germinativo, expondo as plântulas por maior período a fatores adversos, o que pode levar à redução no total de germinação.

Observa-se ainda que a alternância da temperatura também não favoreceu a germinação de sementes de funcho. Esses resultados não

TABELA 1. Resumo de análise de variância para IVG (Índice de Velocidade de Germinação), \% de Germinação, Comprimento de Radícula (cm), Massa Fresca (g) e Massa Seca (g) de sementes de Foeniculum vulgare Miller. Cáceres - MT, 2013.

\begin{tabular}{ccccccc}
\hline Fontes de variação & GL & IVG & \% Germinação & Comp. Radícula & Massa Fresca & Massa Seca \\
\hline Substrato & 2 & $0,13^{\text {Ns }}$ & $50,00^{\text {Ns }}$ & $13,34^{\text {Ns }}$ & $0,0015^{\text {Ns }}$ & $0,0000^{\text {Ns }}$ \\
Temperatura & 1 & $22,54^{* *}$ & $5520,66^{* *}$ & $407,92^{* *}$ & $0,0388^{* *}$ & $0,0000^{* *}$ \\
Subs. x Temp. & 2 & $0,07^{\text {Ns }}$ & $100,66^{\text {Ns }}$ & $7,34^{\text {Ns }}$ & $0,0017^{\text {Ns }}$ & $0,0000^{\text {Ns }}$ \\
Resíduo & 18 & 0,16 & 61,11 & 3,82 & 0,0008 & 0,0000 \\
\hline CV\% & & 12,86 & 10,35 & 26,17 & 53,21 & 37,15 \\
\hline
\end{tabular}

**= Significativo a $1 \%$ de probabilidade. ${ }^{\text {Ns }}=$ Não significativo

TABELA 2. Índice de velocidade de germinação (IVG), Porcentagem de Germinação (\%) de sementes e Comprimento de Radícula, Massa Fresca e Massa Seca de plântulas de Foeniculum vulgare Miller, submetidas a diferentes substratos e temperaturas.

\begin{tabular}{cccccc}
\hline Substrato & IVG & Germinação (\%) & Comprimento Radícula & Massa Fresca (g) & Massa Seca (g) \\
\hline Areia & $3,24 \mathrm{a}$ & $78,00 \mathrm{a}$ & $6,38 \mathrm{a}$ & $0,0623 \mathrm{a}$ & $0,0050 \mathrm{a}$ \\
Vermiculita & $3,21 \mathrm{a}$ & $73,00 \mathrm{a}$ & $7,14 \mathrm{a}$ & $0,0380 \mathrm{a}$ & $0,0036 \mathrm{a}$ \\
Papel & $3,01 \mathrm{a}$ & $76,00 \mathrm{a}$ & $8,89 \mathrm{a}$ & $0,0615 \mathrm{a}$ & $0,0042 \mathrm{a}$ \\
Temperatura & & & & & \\
$20^{\circ} \mathrm{C}$ & $4,12 \mathrm{a}$ & $91,00 \mathrm{a}$ & $11,59 \mathrm{a}$ & $0,0137 \mathrm{~b}$ & $0,0058 \mathrm{a}$ \\
$25^{\circ}-30^{\circ} \mathrm{C}$ & $2,18 \mathrm{~b}$ & $61,00 \mathrm{~b}$ & $3,35 \mathrm{~b}$ & $0,0941 \mathrm{a}$ & $0,0027 \mathrm{~b}$ \\
\hline $\mathrm{CV}(\%)$ & 12,86 & 10,35 & 26,16 & 53,21 & 37,15 \\
\hline
\end{tabular}

As médias seguidas da mesma letra na coluna não diferem entre si pelo teste de Tukey, a 1\% de probabilidade. 
corroboram os recomendados por Meneghello et al. (2002), que indicaram a temperatura de $20-30^{\circ} \mathrm{C}$ para a germinação de sementes da espécie.

Ainda analisando-se a Tabela 2, observouse maior comprimento de radícula para a temperatura constante de $20^{\circ} \mathrm{C}$. Já a massa fresca foi o único parâmetro em que a temperatura de $25-30^{\circ} \mathrm{C}$ alternada $(0,0941 \mathrm{~g})$ foi superior à temperatura de $20^{\circ} \mathrm{C}$ constantes $(0,0137 \mathrm{~g})$. De acordo com Nakagawa (1999), lotes com menor germinação tendem a apresentar maiores valores de massa seca de plântulas que lotes com germinação maior, talvez por usufruírem de maior espaço nas caixas de germinação.

Para a massa seca, observa-se maior média para a temperatura constante de $20^{\circ} \mathrm{C}$. Não houve influência dos diferentes substratos em nenhum dos parâmetros avaliados.

\section{CONCLUSÃO}

Recomenda-se para germinação de sementes de funcho (Foeniculum vulgare) a temperatura de $20^{\circ} \mathrm{C}$ constante. A germinação de sementes de funcho (Foeniculum vulgare) não é influenciada pelos tipos de substratos testados.

\section{REFERÊNCIAS}

BEWLEY, J.D.; BLACK, M. Seeds: physiology of development and germination. 2.ed. New York: Plenum, 1994. 445p.

BRASIL. MINISTERIO DA AGRICULTURA, PECUARIA E ABASTECIMENTO. Regras para análise de sementes. 1.ed. Mapa/ACS. 2009, 399p.

CARNEIRO, J.W.P.; GUEDES,T. A. Influência da temperatura no desempenho germinativo de sementes de cenoura (Daucus carota L.), avaliada pela função de distribuição de Weibull. Revista Brasileira de Sementes. v.14, n.2, p. 207-213, 1992.

CARVALHO, N.M.; NAKAGAWA, J. Sementes: ciência, tecnologia e produção. 4.ed. Campinas: Fundação Cargil, 2000. 588p.

CRUZ, C.D. Programa Genes: biometria. Versão Windows; aplicativo computacional em genética e estatística. 1.ed. Viçosa: Editora UFV, 2006. 382p.

FERREIRA, D.F. SISVAR: um programa para análises e ensino de estatística. Revista Symposium, v.6, p. 36-41, 2008.
IKUTA, A.R.Y.; BARROS, I.B.I. Influência da temperatura e da luz sobre a germinação de marcela (Achyrocline satureioides Lam.). Pesquisa Agropecuária Brasileira, v.31, n.12, p.859-862, 1996.

LABOURIAU, L.G. A germinação das sementes. 1.ed. Washington: OEA, 1983. 174p.

LORENZI, H.; MATOS, F.J.A. Plantas medicinais do Brasil: Nativas e Exóticas cultivadas. 1.ed. Nova Odessa: Instituto Plantarum, 2002. 544p.

MAGUIRE J.D. Seep of germination-aid seedling emergence and vigor. Crop Science, v.2, p.176-177, 1962.

MARTINS G.N.; et al., Efeito da luz e da temperatura na germinação de sementes de Chenopodium ambrosioides L. Revista Brasileira de Plantas Medicinais, v.9, n.4, p.62-67, 2007.

MARTINS, E.R.; CASTRO, D.M.; CASTELLANI, D.C.; DIAS, J.E. Plantas Medicinais. 1.ed. Viçosa: UFV, 1998. 220p.

MAYER, A.M.; POLJAKOFF-MAYBER, A. The germination of seeds. 2.ed. Oxford: Pergamon Press, 1989. 192p.

MENEGHELLO, G.E.; et al., Veracidade da germinação indicada nas embalagens de sementes de espécies medicinais. Revista Brasileira de Sementes, v.24, n.1, p.5-10, 2002.

MENEZES, N.L.; et al., Qualidade fisiológica de sementes de alface submetidas a diferentes temperaturas em presença e ausência de luz. Ciência Rural, v.30, n.6, p.941-945, 2000.

NAKAGAWA, J. Testes de vigor baseados no desempenho de plântulas. In: KRZYZANOWSKI, F.C.; VIEIRA, R.D.; FRANÇA NETO, J.B. (Ed.) Vigor de sementes: conceitos e testes. Londrina: Abrates. 1999. p.1-24.

POPINIGIS, F. Fisiologia da semente. 1.ed. Brasília: Agiplan, 1977. 209p.

SHULL, C.A. Temperature and rate of moisture intake in seeds. The Botanical Gazete, v. 69, n.5, p.361390, 1920.

STEFANELLO, R.; et al., Efeito da luz, temperatura e estresse hídrico no potencial fisiológico de sementes de funcho. Revista Brasileira de Sementes, v.28, n.2, p.135-41, 2006.

TAKARASHI, L.S.A.; et al., Germinação de sementes de erva-doce armazenadas em diferentes ambientes, embalagens e submetidas a períodos de embebição. Horticultura Brasileira, v.18, p.937-938, 2000.

TEIXEIRA, M.S.; CUNHA, S.B.T.; MATTOS, M.B.; SANTANA, D.G.; RANAL, M.A. Número de sementes para teste de germinação de aquênios de ervadoce (Pimpinella anisum L.). In: XIII CONGRESSO BRASILEIRO DE SEMENTES, 13., 2003, Londrina. Anais... Londrina: ABRATES, 2003. p.408. 